\title{
BMJ Open Characteristics of eye injuries, medical cost and return-to-work status among industrial workers: a retrospective study
}

\author{
Rokiah Omar (i) , ${ }^{1}$ Nur Syamilah Anan, ${ }^{1}$ Izmel Azim Azri, ${ }^{1}$ Chiranjib Majumder, ${ }^{1}$ \\ Victor Feizal Knight ${ }^{2}$
}

To cite: Omar R, Anan NS, Azri IA, et al. Characteristics of eye injuries, medical cost and return-to-work status among industrial workers: a retrospective study. BMJ Open 2022;12:e048965. doi:10.1136/ bmjopen-2021-048965

- Prepublication history for this paper is available online. To view these files, please visit the journal online (http://dx.doi org/10.1136/bmjopen-2021048965).

Received 19 February 2021 Accepted 10 December 2021

Check for updates

(c) Author(s) (or their employer(s)) 2022. Re-use permitted under CC BY-NC. No commercial re-use. See rights and permissions. Published by BMJ.

${ }^{1}$ Optometry \& Vision Science Program, Faculty of Health Sciences, Universiti Kebangsaan Malaysia, Kuala Lumpur, Malaysia

${ }^{2}$ Faculty of Medicine and Defence Health, National Defence University of Malaysia, Kuala Lumpur, Malaysia

Correspondence to

Dr Rokiah Omar;

r_omar@ukm.edu.my

\section{ABSTRACT}

Objective The aim of this study is to determine the characteristics of eye injuries, medical costs and returnto-work status among industrial workers to provide better vision rehabilitative services.

Setting Nationwide data from the Social Security Organisation (SOCSO) of Malaysia.

Participants A stratified random sample of workers registered with the SOCSO of Malaysia with documentation of eye injury.

Primary and secondary outcome

measures Characteristics of eye injuries and medical costs related to eye injury (primary) and return-to-work status (secondary).

Results A total of 884 from 8861 case files workplace accidents involving eye injury registered with Social Security Services (SOCSO) were identified. The mean age was $35 \pm 10$ years and the highest incidence of workrelated eye injury occurred in the age group 30-39 years and among Malay ethnics. Males are affected more than females' workers. The highest cause of eye injury was the impact from a moving object excluding falling objects $(89.2 \%)$ and anterior segment injuries occurred more than posterior segment injuries. The total direct and Indirect medical cost was RM1 108098.00 (US\$316 599.40) and RM4 150140.00 (US\$1 185754.20 ) for 884 cases. Conclusion The majority of workers suffered from the low level of eye injury. A significant relationship was found between the severity of eye injury and employee work status. The indirect cost of medical and vision rehabilitation was higher than the direct cost. Awareness and vision rehabilitation programmes at the workplace need to be addressed for better prevention and rehabilitative service.

\section{INTRODUCTION}

The human eye has a physiologically highly precise and distinct role. To perceive images of objects clearly, it is necessary for all components of the eye to work normally. Good visual function is essential in almost all tasks in activities of daily living, especially those related to employment. Eye injury is one of the major causes of blindness that worldwide encompasses nearly half a million people, while many others experience partial loss of vision from these injuries. ${ }^{1}$ Eye injury is a primary

\section{Strengths and limitations of this study}

- This study has compared eye injuries based on industry type and by states in Malaysia which were not done before too extensively.

- This study also highlighted the average medical cost of treating patients with work-related eye injuries and the return-to-work status among industrial workers in Malaysia which was not reported earlier.

- Moreover, it also highlighted the need for vision rehabilitation which was not addressed by the earlier studies.

- The details of vision rehabilitation are not considered for further analysis because it was a retrospective case files study.

- Important components of vision named stereopsis, contrast sensitivity, colour vision and visual field data not included in the study.

cause of unilateral vision loss in developing countries. It has been found that males are more likely to have eye injury compared with females and this is a trend that is noticed even from childhood. Moreover, eye injuries tend to be more associated with lower socioeconomic conditions. ${ }^{1}$ Each year the USA reports approximately 2.4 million new eye injury cases. ${ }^{2}$ Out of these, $40000-60000$ patients eventually experience blindness due to eye injuries. ${ }^{34}$ The global pattern of eye injuries shows approximately 55 million eye injuries occurring causing work day losses of more than 1 day every year. Out of these injury occurrences, annually 750000 cases will require in-patient care. Furthermore, approximately 1.6 million people become blind from these eye injuries with an additional 2.3 million people develop bilateral low vision. In Pahang, Malaysia the prevalence of eye injury was $9.80 \% .^{5}$

Eye injury is commonly occurring in the workplace $(38.50 \%)$, road accidents $(20.50 \%)$, sports $(29 \%)$ and during quarrel $(5 \%)$. A penetrating injury occurred in $72.50 \%$ cases whereas blunt injury accounted 
for $27.50 \%$ cases. $^{6}$ A study conducted in Brazil reported $56.70 \%$ of eye injuries occurred in the workplace followed by those occurring at home $(28.30 \%)$. Surprisingly, it was found that $82.90 \%$ of the victims of eye injury did not wear any eye-protective devices (EPD) at the time of their accidents. ${ }^{7}$ A review study from Malaysia reported a higher prevalence of eye injury among males with their mean age being 35 years. The common place where eye injury was suffered among adults was in the workplace while for children it was at home. ${ }^{8}$ An earlier study reported that work-related eye injuries in east Malaysia accounted for $36.90 \%$ of the total eye injury cases reported. However, work-related eye injuries reported in Singapore represented $71.40 \%$ of cases of total eye injury visiting casualty units there. Out of all the eye injuries reported, $90 \%$ arose from industrial activities such as drilling, grinding and cutting metals. ${ }^{9}$ A earlier prospective study conducted in Malaysia reported work-related eye injury rate of $43.6 \%$ among patients attended the medical centre. The causes of eye injury involved the usage of high-powered machines $(30.8 \%)$, motor vehicle accidents $(23.10 \%)$ and domestic accidents $(17.70 \%)$. However, only $2.50 \%$ used an EPD at the time of injury. ${ }^{10}$ Madhusudhan et al in his study reported that eye injuries most commonly involved the home $(51.80 \%)$ and workplace $(23.40 \%)$ in Malaysia. ${ }^{11}$ Similarly, a previous study by Mallika et al among adults in Kuching, Sarawak also found that areas such as home $(34.30 \%)$ and industrial premises $(31.80 \%)$ were the most common locations where eye injury occurred. ${ }^{12}$

Eye injuries can cause the loss of working days among workers which causes a loss of productivity and this then becomes a burden to the economy. It is important to understand the implication of eye injuries and how it affects workers, family members, industries and the nation. Emphasis on providing vision rehabilitation will help affected workers to continue their work. ${ }^{13}$ Vision rehabilitation includes the prescription of glasses, contact lenses, prisms and low vision rehabilitative services. However, return to work requires a multidisciplinary approach and can be a challenge to implement comprehensively. Little information is available of the characteristics of eye injuries, their associated medical costs and return-to-work status among industrial workers who get injured. ${ }^{13}$ We postulate that comprehensive visual rehabilitation services for industrial workers with eye injuries needs to be available in order that productivity can be maintained. Therefore, the objective of this study is to identify the characteristics of eye injuries, medical costs and return-to-work status among industrial workers in Malaysia so that better visual rehabilitation services can be recommended and provided for.

\section{METHODOLOGY}

This was a retrospective study conducted using case records of eye injuries among industrial workers registered with the Social Security Organisation (SOCSO). Permission to conduct this research was also obtained from the Medical Division of SOCSO Headquarters and the data authorised for use was those in the calendar years 2004-2008. SOCSO was chosen as the source of reference for secondary data files because SOCSO has the most comprehensive collection of work place medical records in Peninsular Malaysia. SOCSO appoints trained medical doctors as their panel doctors organisation and these doctors must completed a comprehensive 72-hour training programme before being certified as an occupational health doctor and eligible to be registered with the Department of Occupational Health and Safety, Ministry of Human Resources.

SOCSO is a statutory body set up its own remuneration system to provide medical and financial assistance to workers whose ability to work have been affected by accident or illness. The main function of SOCSO is to provide social security protection to employees and their dependants through the Employment Injury Scheme and the Invalidity Scheme (Act 4). All workers will contribute to the scheme and the employers also have to contribute as well. The workers include private workers, contract and temporary government officers. The workers are mandatory to contribute to the SOCSO and register to the SOCSO according to the law of Malaysia. The Employment Injury Scheme provides protection to employees from occupational injuries including occupational diseases and commuting accident during travel in connection with employment. The Invalidity Scheme provides 24-hour protection to employees against invalidity or death due to causes occurring outside working hours. SOCSO protection scheme provide cash benefits to employees and their dependants in the event of unforeseen incidents, in addition to providing medical treatment, physical rehabilitation or vocational training. SOCSO also conducts accident prevention activities through occupational safety and health awareness programmes among employees and employers. Besides, Self-Employment Social Security Scheme (Act 789) provided protection under the Employment Injury Scheme to self-employed taxi drivers and individuals providing similar services including Uber and Grab Car drivers. Other services provided is the Employment Insurance System Act (EIS) (Act 800) for the purpose of protecting and helping workers who have lost their employment using two main components namely, Employment Insurance and Employment Services to promote active labour market policies. The EIS is a new protection scheme for workers who have lost their employment by replacing lost income, providing reskilling and upskilling training to enable them to find new jobs as well as providing job-search services, so that they can gain suitable employment more expediently. To qualify for such benefits, the insured person must fulfil the contribution eligibility in accordance with the claim, that is, a minimum of 12 months' contribution in a period of 24 months and such benefits shall be payable beginning 1 January 2019. However, the insured person must meet the eligibility requirements and must be capable and ready to work as well as actively search for employment. 
The panel of doctors are appointed by the SOCSO organisation. When any injury reported by the worker, they need to go and see the doctor allotted from the panel clinic or hospital. The report given by the panel is then transcribed into electronic form. SOCSO also helps workers' dependents in the event of their death through a pension scheme. Inclusion criteria for this study included eye injury cases occurring in Peninsular Malaysia, cases being eye injury related to the workplace reported between 2004 and 2008.

\section{Patient and public involvement}

No patient involved. Only case files were reviewed and analysed.

\section{Sampling technique and methods}

The cases were selected through a process of stratified random sampling where every 10 cases files were selected as stratum and one case file from each stratum was selected randomly. Cases of workplace related eye injuries that did not occur in Peninsular Malaysia, and not reported between 2004 and 2008 were excluded from this study. All case files identified for inclusion were kept confidential and anonymous. The information extracted from the case files included date of first consultation, age and gender, cause of the eye problem suffered, location of the eye injury, level of vision, date and time of hospital admission, clinical diagnosis, eye and vision recovery data, eye function data, available medical care and costs involved, recovery time and number of days the subject was not able to work. The eye injury classification used for this study was adopted from the standard international classification system, that is, the Birmingham Eye Injury Terminology System and modified to come up with the suitable SOCSO classification and the classification of 21 industry types in Malaysia was based on the Malaysian Standard Industry Classification 2008 V.1.0 used by the Department of Statistics Malaysia. ${ }^{14}$ The International Classification of Diseases 11 (2018) classified visual impairment into mild impairment (visual acuity, VA $<6 / 12-6 / 18$ ), moderate impairment (VA $<6 / 18-$ $6 / 60$ ), severe impairment (VA $<6 / 60-3 / 60$ ) and blindness $(\mathrm{VA}<3 / 60) .{ }^{15}$ The severe impairment and blind was merged into severe impairment category for this study. The data were analysed using IBM SPSS Statistics for Windows, V.25. Descriptive tests were used to analyse the study data covering mean, percentage, median and SD. The relationship between the severity of eye injury and the ability of the employee to return to work was analysed using $\chi^{2}$ Test.

\section{RESULTS}

\section{Characteristics of work-related eye injury}

From 2004 to 2008, a total of 8861 workplace accidents involving eye injuries were registered with SOCSO. A total of 884 eye injury case files were randomly selected which fulfilled the selection criteria for this study. A summary of information on the worker profile, severity of workrelated eye injury and work status based on age among industrial workers registered with SOCSO is shown in table 1 .

Most of these workplace eye injury cases registered with SOCSO involved male workers in a ratio of 14:1 compared with female workers. The average age of all employees was $35 \pm 10$ years. The average age for male and female workers were $34 \pm 10$ and $38 \pm 12$ years. The highest proportion of work-related eye injuries occurred in the age group of 30-39 years old. In terms of ethnicity, Malays had the highest proportion of work-related eye injury cases.

The eye injury cases were categorised according to their causes and the characteristics of work-related eye injury experienced by the injured workers. The causes of workrelated eye injury and the characteristics of work-related eye injury were divided into nine and eight subtypes, respectively. The highest number of eye injuries occurred from incidents that resulted in the impact from a moving object but excluding incidents that involved a falling object $(89.20 \%)$. These moving objects include fragments or flying particles near or within the working environment of the worker. Eye surface injury $(51.60 \%)$ were the most common cause of injury among these industrial workers. Eye surface injuries include causes such as splinters entering the eyes, corneal abrasions, scratches and bites by non-invasive insects that lead to injuries to the surface of the eye and adnexa. The details of the types and characteristics of work-related eye injury among industrial workers are shown in table 2. The characteristics of the work-related eye injury is categorised into five categories which include the anatomy of the eye, affected eye, level of severity of injury experienced, onset of treatment given and level of vision of the worker with the eye injury.

About $70 \%$ of the work-related eye injuries in Peninsular Malaysia that were filed with SOCSO from 2004 to 2008 affected the anterior segment of the eye. Out of all these anterior segment injuries, corneal injury was the highest $(53.40 \%)$. In this study, the left eye $(47.40 \%)$ was more affected than the right eye $(42.20 \%)$. The severity of work-related eye injury was categorised into three distinct levels, namely mild, moderate and severe levels. Monocular work-related eye injuries were found more likely to occur than binocular eye injury $\left(\chi^{2}=566.69\right.$, $\mathrm{df}=3, \mathrm{p}<0.001)$. Majority, that is, $45.00 \%$ workers in this study suffered from mild level work-related eye injuries (table 2). Analysis using the $\chi^{2}$ test showed a significant difference $(\chi 2=99.99, \mathrm{df}=2, \mathrm{p}<0.001)$ between the severity of the work-related eye injury levels. In terms of time of treatment for the injury, about $70 \%$ of workers received their treatment on the same day $(0.8 \pm 3.5$ days $)$ as the date of their work-related eye injury while the remaining mostly sought treatment within 3 days of injury. The majority of the work-related eye injury workers had good to mild level of visual impairment on the day of their initial VA assessment. 


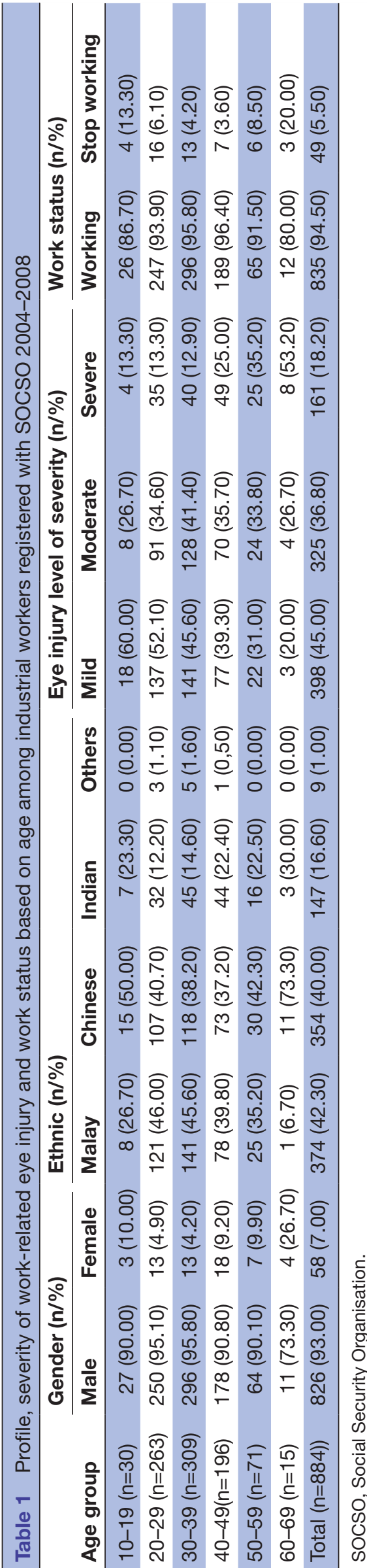

Table 2 Types and characteristics of work-related eye injury among industrial workers registered with SOCSO 2004-2008

\begin{tabular}{lrr}
\hline Characteristics & $\begin{array}{l}\text { No } \\
(\mathbf{n}=\mathbf{8 8 4})\end{array}$ \\
\hline Anatomy of eye & & \\
\hline Cornea & 472 & 53.4 \\
\hline Multiple injury & 232 & 26.2 \\
\hline Conjunctiva & 98 & 11.1 \\
\hline Eyelid & 30 & 3.4 \\
\hline Eyebrow & 20 & 2.3 \\
\hline Crystalline lens & 7 & 0.8 \\
\hline Orbital & 7 & 0.8 \\
\hline Retina & 6 & 0.7 \\
\hline Sclera & 4 & 0.5 \\
\hline Anterior chamber & 4 & 0.5 \\
\hline Nasolacrimal gland & 2 & 0.2 \\
\hline Uvea & 1 & 0.1 \\
\hline Optic nerve & 1 & 0.1 \\
\hline Affected eye & & \\
\hline Left eye & 419 & 47.4 \\
\hline Right eye & 373 & 42.2 \\
\hline Both eye & 75 & 8.5 \\
\hline No record & 17 & 1.9 \\
\hline
\end{tabular}

Eye injury level of severity

\begin{tabular}{lcc}
\hline Mild & 530 & 45 \\
\hline Moderate & 236 & 36.8 \\
\hline $\begin{array}{l}\text { Severe } \\
\text { Causes }\end{array}$ & 118 & 18.2 \\
$\begin{array}{l}\text { Impact from a moving object } \\
\text { excluding falling objects }\end{array}$ & 788 & 89.2 \\
\hline $\begin{array}{l}\text { Impact from a static object } \\
\text { Impact from a falling object }\end{array}$ & 33 & 3.7 \\
$\begin{array}{l}\text { during work } \\
\text { Impact from a moving object }\end{array}$ & 30 & 3.3 \\
\hline $\begin{array}{l}\text { Falling from a higher place } \\
\text { Falling from the same height or }\end{array}$ & 7 & 1 \\
\hline lower place & 7 & 0.8 \\
\hline $\begin{array}{l}\text { Other impacts from falling object } \\
\text { Exposure to ionising radiation }\end{array}$ & 5 & 0.8 \\
\hline Other accidents & 4 & 0.6 \\
\hline Types of eye Injury & 1 & 0.1 \\
\hline Eye surface injury & & \\
\hline Other injury & 456 & 51.8 \\
\hline Blow & 182 & 20.6 \\
\hline Burn & 105 & 11.8 \\
\hline Bruise & 88 & 10.1 \\
\hline Radiation effect & 46 & 5.3 \\
\hline & 3 & 0.3 \\
\hline
\end{tabular}




\begin{tabular}{|c|c|c|c|c|}
\hline \multicolumn{3}{|l|}{ Characteristics } & $\begin{array}{l}\text { No } \\
(n=884)\end{array}$ & $\%$ \\
\hline \multicolumn{2}{|l|}{ Fracture } & & 2 & 0.2 \\
\hline \multicolumn{5}{|l|}{ Start treatment day } \\
\hline \multicolumn{2}{|l|}{ Same day } & & 602 & 68.3 \\
\hline \multicolumn{2}{|l|}{$\leq 3$ days } & & 241 & 27.3 \\
\hline \multicolumn{2}{|l|}{$\leq 7$ days } & & 26 & 2.9 \\
\hline \multicolumn{2}{|l|}{$\leq 14$ days } & & 7 & 0.8 \\
\hline \multicolumn{2}{|l|}{$\leq 30$ days } & & 4 & 0.5 \\
\hline \multicolumn{3}{|l|}{$>30$ days } & 4 & 0.5 \\
\hline \multirow{2}{*}{$\begin{array}{l}\text { Vision acuity } \\
\text { level }\end{array}$} & \multicolumn{2}{|c|}{$\begin{array}{l}\text { Initial } \\
\text { assessment } \\
(n=266)\end{array}$} & \multicolumn{2}{|c|}{$\begin{array}{l}\text { Final assessment } \\
(n=360)\end{array}$} \\
\hline & RE & LE & RE & LE \\
\hline Good (6/4.5-6/6) & $39.80 \%$ & $38.30 \%$ & $66.70 \%$ & $61.70 \%$ \\
\hline Mild (6/7.5-6/18) & $30.80 \%$ & $33.10 \%$ & $21.70 \%$ & $23.10 \%$ \\
\hline $\begin{array}{l}\text { Moderate } \\
(<6 / 18-6 / 60)\end{array}$ & $14.70 \%$ & $14.70 \%$ & $3.90 \%$ & $6.90 \%$ \\
\hline $\begin{array}{l}\text { Severe }(<6 / 60- \\
\text { NPL) }\end{array}$ & $14.70 \%$ & $13.90 \%$ & $7.80 \%$ & $8.30 \%$ \\
\hline
\end{tabular}

LE, left eye; NPL, no perception of light; RE, right eye; SOCSO, Social Security Organisation.

\section{Trend of work-related eye injury}

Figure 1 shows a decreasing trend of eye injury occurring from 2004 to 2008. The percentage of employmentrelated eye injuries when analysed by industry type, the highest number of cases were in manufacturing (38.70\%), followed by trading $(15.30 \%)$ and public services $(15.0 \%)$. On the other hand, the lowest percentage of cases were from the mining $(0.90 \%)$, financial $(0.60 \%)$ and electrical, gas and water industries $(0.10 \%)$ as shown is in figure 2.

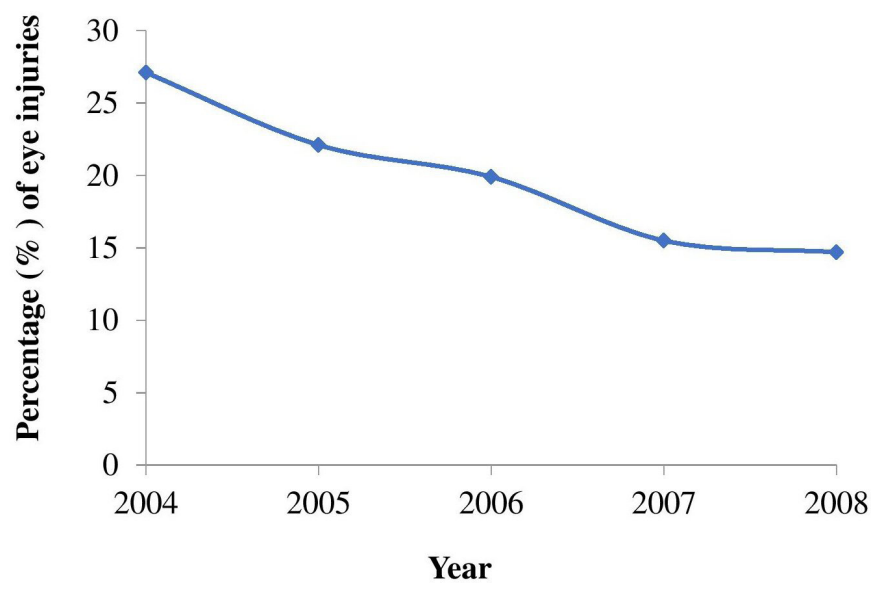

Figure 1 The changes of eye injuries in percentage from 2004 to 2008 registered with SOCSO. SOCSO, Social Security Organisation.

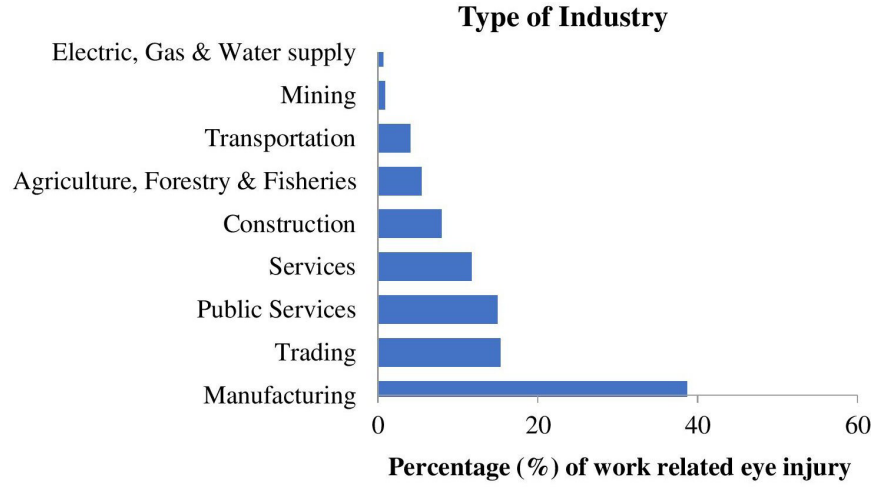

Figure 2 Percentage of workers with work-related eye injury among subjects registered with SOCSO 2004-2008. SOCSO, Social Security Organisation.

When the proportion of eye injuries was analysed by their state location of occurrence in Peninsular Malaysia, the State of Selangor $(21.40 \%)$ had the highest number of cases of eye injury and state of Terengganu $(0.90 \%)$ showed lowest as shown in table 3 . The work-related eye injury had an increased trend in public services from the year 2004 to 2008 as shown in figure 3.

\section{Method, cost and efficacy of recovery}

The manner of recovery, cost of medical expenses and the rate of injured workers returning to work are shown in table 4. The costs of treatment determined in this study refers to the standardised maximum reimbursable hospital rates used by SOCSO for payment for treatment of workplace injury. Whereas the types of treatment received by workers with eye injuries registered in SOCSO are listed in table 4.

Worker recovery from injury is divided into two groups. The first group depicts medical recovery from injury which would include surgery (if needed), outpatient follow-up and medication. The second group depicts vision recovery methods which include spectacles, protheses and recovery references. In the medical recovery group, the type $\mathrm{C}$ and type $\mathrm{B}$ surgery treatment modalities were the most common options reported for treating eye injury ( $>50$ cases). It is also noted that the biggest number of cases were moderate types of eye injuries with moderate types of treatment needed.

The indirect costs are derived from the value of temporary disability or the number of workers' days off from work, and the value of permanent disability or workers' compensation costs. This study showed that $94.50 \%$ workers returned to work after their recovery from injury. However, the remaining $5.50 \%$ did not go back to work as derived from table 5 . The age wise distribution of eye injury severity and occupational status showed the highest percentage of return to work was for the age groups 30-39 years and 40-49 years which were $95.80 \%$ and $96.40 \%$, respectively. Although the severity of injury was found to be higher among workers over the age of 50 years, nonetheless most of them were able to return to work. Whereas, the younger age group, 10-19 years, 
Table 3 Eye injury trends according to the type of industry in each state in Peninsular Malaysia and by age group

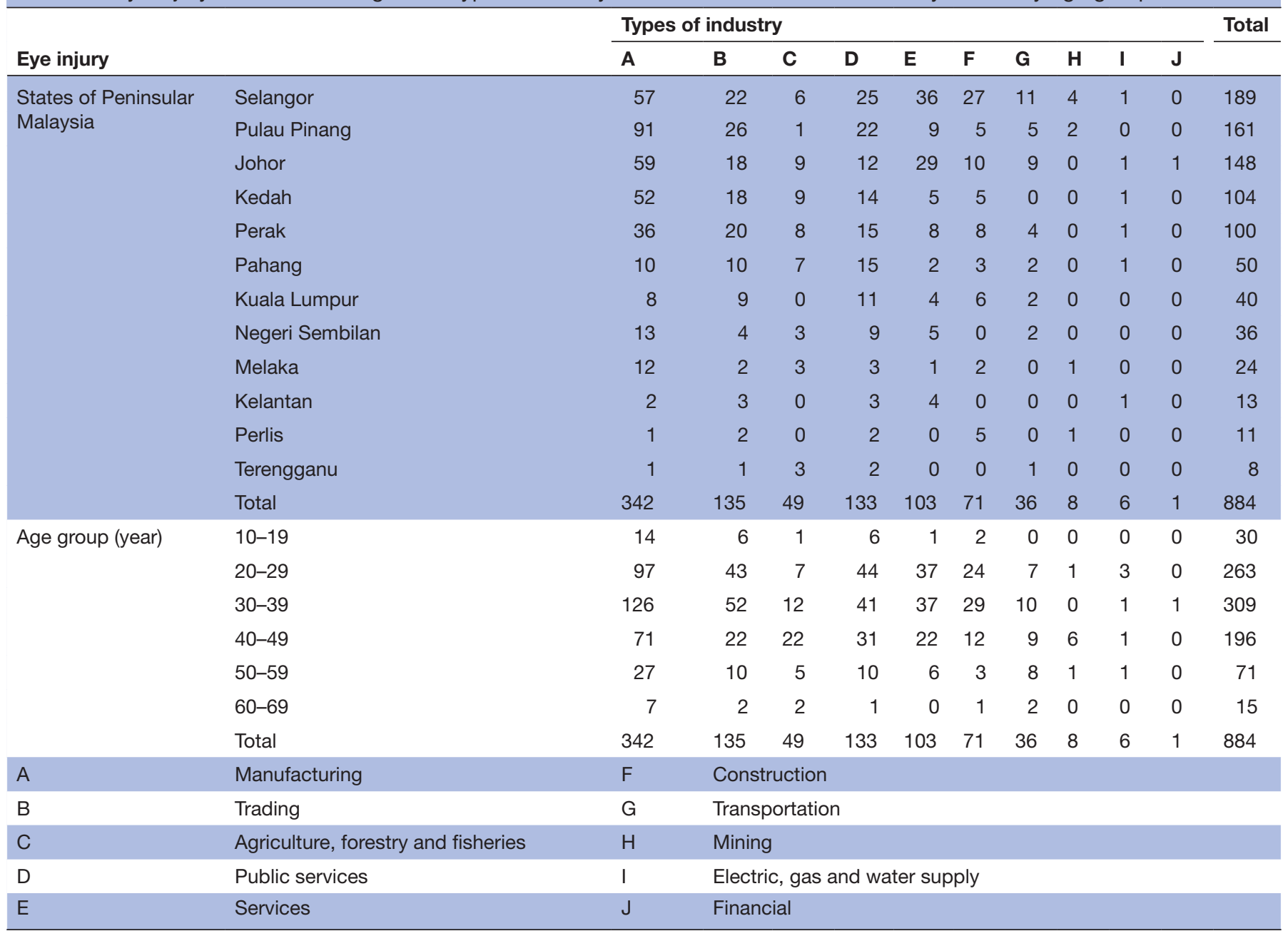

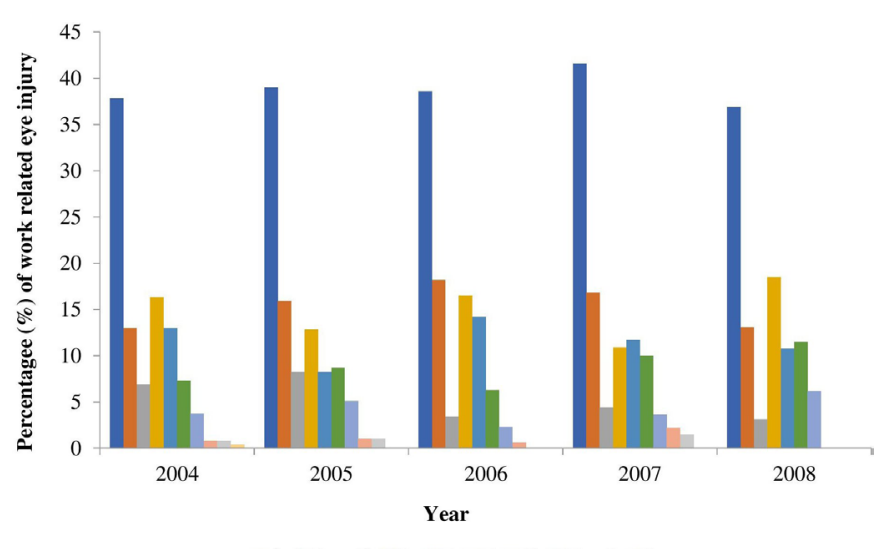

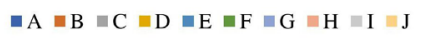

$$
\begin{array}{llrl}
\text { A } & \text { Manufacturing } & \text { F } & \text { Construction } \\
\text { B } & \text { Trading } & \text { G } & \text { Transportation } \\
\text { C } & \text { Agriculture, Forestry \& Fisheries } & \text { H } & \text { Mining } \\
\text { D Public services } & \text { I } & \text { Electric, Gas \& Water supply } \\
\text { E } & \text { Services } & \text { J } & \text { Financial }
\end{array}
$$

Figure 3 The proportion of eye injury by industry for the period 2004-2008 registered with SOCSO. SOCSO, Social Security Organisation. stopped working more often compared with the older age groups except for the age group 60-69 years as shown in table 1 . The total direct and Indirect medical cost was RM1 108098.00 (US\$316 599.40) and RM4 150140.00 (US\$1 185754.20$)$.

Type B included intraocular lens implant keratoplasty: lamellar or penetrating retinal detachment surgery, intraocular foreign body removal, strabismus surgery, repair of severe perforating injuries of the eyeball, glaucoma surgery, dacryocystorhinostomy, dacryocystectomy repair of several lachrymal passages exenteration of orbit.

Type C included cataract extraction: intracapsular and extracapsular, repair of eyelid deformities, extraction of dislocated/subluxated lens, discussion paracentesis excision of orbital or ocular tumours iridectomy: peripheral or optical cryopexy as prophylaxis against retinal detachment and glaucoma evisceration, enucleation, ectropion or enntropion correction, tarsorrhaphy repair of severe laceration of eyelid and/or region around the eyes, pterygium surgery, excision biopsy release of symblepharon/mucous membrane graft, repair of lachrymal puncta or canalicular obstruction, 
Table 4 Estimated medical, and vision recovery cost of 884 industrial workers registered with SOCSO

\begin{tabular}{|c|c|c|c|c|c|}
\hline Cost category & No & Costs (RM) & Costs (US\$*) & Total (RM) & Total (US\$*) \\
\hline Direct costs of medical recovery & & & & 1108098.00 & 316599.40 \\
\hline Surgery B & 64 & 750.00 & 214.20 & 48000.00 & 13714.20 \\
\hline Surgery C & 79 & 500.00 & 142.80 & 39500.00 & 11285.70 \\
\hline Surgery D & 17 & 188.00 & 53.70 & 3196.00 & 913.10 \\
\hline Outpatient (mild cases) & 75 & 40.00 & 11.40 & 3000.00 & 857.10 \\
\hline Outpatient (moderate cases) & 393 & 70.00 & 20.00 & 27510.00 & 786.00 \\
\hline Outpatient (severe cases) & 19 & 100.00 & 28.50 & 1900.00 & 542.80 \\
\hline Medication (mild treatment) & 72 & 50.00 & 14.20 & 17850.00 & 5100.00 \\
\hline Medication (moderate treatment) & 125 & 70.00 & 20.00 & 136268.00 & 38933.70 \\
\hline Medication (severe treatment) & 40 & 100.00 & 28.50 & 254900.00 & 72828.50 \\
\hline Ward cost & - & 32.00 & 9.10 & 540374.00 & 154392.50 \\
\hline \multicolumn{6}{|l|}{ Vision recovery } \\
\hline Spectacles & 25 & 400.00 & 114.20 & 10000.00 & 2857.10 \\
\hline Prosthesis & 6 & 3600.00 & 1028.50 & 21600.00 & 6171.40 \\
\hline Spectacles+prosthesis & 1 & 4000.00 & 1142.80 & 4000.00 & 1142.80 \\
\hline Recovery references & 1 & - & & - & \\
\hline Indirect costs & & & & 4150140.00 & 1185754.20 \\
\hline Value of temporary disability & & & & 805268.00 & 230076.50 \\
\hline Value of permanent disability & & & & 3344872.00 & 955677.70 \\
\hline Total recovery costs & & & & 5258238.00 & 1502353.70 \\
\hline
\end{tabular}

Bold value indicates the total direct, indirect and combined recovery cost in RM and USD.

*US\$1=RM3.5 (average of 2004-2008).

repair of moderate perforating injury of eyeball, laser coagulation

Type D included Incision and curettage of chalazion, excision of granulomas, removal of corneal or conjunctival foreign body catholysis/epilation of trichiasis, repair of minor lacerations of eyelids and/or region around the eyes, syringing/probing of lachrymal apparatus, repair of minor perforating injury of eyeball.

Source of data SOCSO.

\section{Severity of eye injury and effectiveness of vision recovery}

The relationship between the severity of eye injury and the ability of the employee to return to work was analysed. Table 5 displays the relationship between the injured employee (registered with SOCSO) employment status with the severity of the eye injury they experience. It was

Table 5 Frequency of employment status based on severity of work-related eye injury

\begin{tabular}{lrrrrr}
\hline & \multicolumn{3}{c}{ Eye injury level of severity $(\mathbf{n})$} & \\
\cline { 2 - 4 } Work status & Mild & Moderate & Severe & Total \\
\hline Working & 382 & 314 & 139 & 835 \\
Stopped working & 16 & 11 & 22 & 49 \\
Total & 398 & 325 & 161 & 884 \\
\hline
\end{tabular}

$X^{2}=24.94, d f=2, p<0.001$. found that most workers injured in Peninsular Malaysia suffered mild $(n=398)$ and moderate $(n=325)$ eye injuries. Of that number, $96 \%$ of them were able to return to work. In contrast, $14 \%$ of workers with severe eye injuries were unable to return to work. To prove the correlation between this data, a $\chi^{2}$ test was performed. The results of the $\chi^{2}$ test $\left(\chi^{2}=24.94, \mathrm{df}=2, \mathrm{p}<0.001\right)$ showed that there was a significant relationship between the severity of eye injury and employee work status. This indicates that, when the degree of injury of the employee's eyes worsens or the total number of days of sick leave exceeds 1 month, the chances of the workers returning to work declines.

\section{DISCUSSION}

This study showed a male preponderance of eye injuries which is congruent with the study conducted in Malaysia by Soong et al where he found $88.1 \%$ cases occurred among males. Similarly, other studies also supported this male predominance. ${ }^{15} 710-12$ 16-21 The ethnic distribution of cases showed that Malays $(42.30 \%)$ had a higher percentage of work-related eye injury followed by the Chinese, Indian and other ethnicities. The study by Soong et al reported a similar ethnic distribution of eye injury with the percentage of Malay, Indian, Chinese and other ethnicities being $31.90 \%, 12.20 \%, 9.70 \%$ and $2.10 \%$, respectively. ${ }^{10}$ This study found that the highest number 
of eye injuries occurred from impact with a moving object (excluding falling objects) $(89.20 \%$ ), followed by impact from a static object, impact from falling objects during operation (work), and impact from moving objects which contradicted another Malaysian study which reported $30.80 \%$ of injuries were from activities such as grinding or cutting metal $(15.80 \%)$, welding $(6.90 \%)$, hammering on metal $(3.70 \%)$, carpentry $(2.60 \%)$ and nailing $(1.80 \%) .{ }^{10}$ Moreover, injury to the surface of the eye was more common and accounted for $51.60 \%$ of eye injuries. Of the anterior segment eye injuries, corneal injury was the major cause followed by multiple injury causes. These study findings were supported by two other studies also conducted in Malaysia which reported $61.50 \%$ of eye injuries were corneal laceration and other study reporting that the common anatomical site of injury was the cornea $(43.60 \%)$, followed by the conjunctiva $(39.50 \%) .^{510}$

In this study, monocular work-related injuries were more common than binocular injuries and the left eye was more affected compared with the right eye. It was also reported that about $70 \%$ of workers received treatment on the same day while the remainder mostly sought treatment within 3 days of injury. However, an earlier study conducted in Malaysia contradicted these findings where that study found that right eye injury was more common, followed by the left eye and then both eyes but was in agreement with the fact that $73.40 \%$ presented within 24 hours of the injury and that a further $23.90 \%$ presented between 1 and 3 days from the day of the injury. ${ }^{10}$ Furthermore, the trend of eye injury decreased from 2004 to 2008 and the manufacturing industry recorded the highest number of cases of eye injuries, followed by trading and public services. It was noted that Selangor state had the highest number of cases of eye injury followed by Penang. Thus far, no other such study has compared eye injuries based on industry type and by State in Malaysia previously.

In a previous study, the average working day loss was reported as 3.4 days. ${ }^{22}$ The study of Ho et al reported that the duration of hospital treatment was from 4 to 7 days, with the average cost of medical treatment being NT $\$ 43 \quad 609 \pm N T \$ 30 \quad 660 \quad$ (US $\$ 6635.05 \pm$ US $\$ 4664.87$ or US\$1567.46 \pm US\$1102.03). ${ }^{23}$ Another study recorded that over US $\$ 300$ million a year was lost comprising total lost time and income, medical expenses and employee compensation. ${ }^{24}$ Almost $90 \%$ of all occupational eye injuries can be prevented through the use of appropriate safety equipment. Using appropriate safety equipment can indirectly save total costs of eye injuries such as the related legal fees, the cost of repairing the damage resulting from the circumstances related to the injury in the work premises and the necessary employee training fees has been estimated at more than US $\$ 934$ million annually in America. ${ }^{25}$ In this study, it was found that the costs of medical and vision recovery was about Ringgit Malaysia 5 million (about US $\$ 1.2$ million) where the direct costs amounted to more than Ringgit Malaysia 1 million (about US\$300 000) and indirect costs were more than Ringgit Malaysia 4 million (about US $\$ 1.1$ million). This study provides an understanding of the economic importance of work-related eye injuries in Malaysia which has not been explored before. Both employers and employees must be aware of the relationship between visual health and productivity in the workplace. Employees who experience a significant decrease in their vision can contribute to increased rates of negligence in the workplace and losses of working days. Negligence can make a work premise a place where workers are at high risk of danger. This situation happens because of employees with a decrease in their visual ability may find it difficult to adapt to their reduced visual state and this in turn can lead to frustrations with their jobs or tasks. This employee than would have to deal with fatigue, headaches and constant stress on a daily basis caused by their vision dysfunction. This circumstance may then lead to the employee's income becoming compromised if this situation persists over a period of time. If there are many workers involved, this situation can then threaten the economic stability of industries and eventually countries while being likely to cause a rising unemployed population. The employer also bears huge losses from this loss of experienced and trained work persons who face these vision limitations.

In this study, it was found that about $96 \%$ of workers suffering from eye injury suffered from low to moderate injury which in turn increased their indirect medical costs in comparison to their direct medical costs and their chances of returning to work. Although 14\% of workers had suffered severe injury, still the percentage of their not returning to work was low, being $5.50 \%$. There are a number of factors that can affect the severity of an employee's eye injury. These factors include the quality of safety protection devices, mechanisms of accidents, types of eye injuries, when treatment was started, the type of medical treatment given and so on. For those with low severity injuries, the visual status of these injured workers was assisted and improved through refractive error correction using glasses or contact lens. This method, however, can only help in certain cases, depending on the effects of the injury sustained. Work-related eye injuries are not only affected by refractive errors, but also includes visual field problems, stereopsis and other more extensive and complicated problems. The rehabilitation is not just prescribing glasses, there are multiple factors that decides the success rate of the rehabilitation. The rehabilitation performed needs to be tailored to address all the problems encountered by the injured worker including any loss of field of vision or eye muscle imbalance. The results of the $\chi^{2}$ test on the data from the injured workers in this study showed that the degree of severity of the eye injuries affected that injured worker's ability to return to work. The greater the severity of the eye injury, the chances of that worker returning to work became less. Vision rehabilitation therapy can improve an injured employee's vision to a better level. It must be noted that since most of these injured workers receive an injury involving only one eye, they are typically not eligible to be classified as an individual with limited vision (since the uninjured eye 
has typically normal vision, thus not fulfilling the criteria for limited vision.

Adaptation to vision loss among workers usually occurs rapidly. This is because occupational eye injuries usually happen to younger adult individuals and those who have the physical ability to continue working. This can be seen from the findings of this study where most of the injured workers return to work. This situation has the potential to create a higher risk to employees with their current vision status not reaching the actual standards needed for the job they do, especially when they need to handle or operate hazardous equipment. Often there is no specific assessment of the safety of the employee in his duties when they return to duty after injury.

To further strengthen Malaysia's position within the global economic community with strong and progressive economic and industrial development policies, worker safety issues in the workplace should be given due attention and should address worker safety from all angles. This should not only involve just accident prevention measures in workplaces but should also address postinjury rehabilitation for those who are injured in their course of their work which should also encompass vision recovery methods. The experience from other developed countries can be studied, and wherever appropriate these experiences can implement prudently in the Malaysian work environment.

The limitation of the study includes lack of data availability after the year 2008. This descriptive study was not reported relative to an underlying study base, making it difficult to assess whether certain groups of workers were more likely to have eye trauma. Besides, other important components of vision named stereopsis, contrast sensitivity, colour vision and visual field data not included in the study. However, the details of vision rehabilitation are not considered for further analysis because it was a retrospective case files study. Due to the retrospective observational study design, an inherent bias can be possible and it can be overcome by considering a prospective study in future.

\section{CONCLUSION}

This study concludes that males are more affected than females and have highest percentage of work-related eye injuries. It was observed that work-related eye injuries were most likely to occur among Malay workers compared with the other Malaysian ethnicities. The highest number of eye injuries arose from the impact of moving objects (excluding those caused by falling objects) (89.20\%), followed by eye surface injury (51.60\%) where commonly corneal injury was seen. The State of Selangor had the highest number of cases of eye injury followed by the state of Penang over the study period, 2004-2008. It was found that in this period, more workers suffered from eye injuries in the low category $(45.00 \%)$ more followed by the moderate $(36.80 \%)$ and severe $(18.20 \%)$ categories. About $70 \%$ workers received treatment for their eye injuries on the same day as their injury occurred while the remaining mostly sought treatment within 3 days of injury. Indirect medical costs were found to be higher than direct medical costs and the percentage of workers returning to work after receiving treatment was $94.50 \%$. Awareness and vision rehabilitation programme at work place need to be address for a better prevention and rehabilitative service.

Acknowledgements The author would like to thank the Social Security Organisations (SOCSO) Malaysia in providing data access for the years 2004-2008.

Contributors R0: designed the manuscript construct, interpreted investigative data, wrote the manuscript and critically reviewed the manuscript. Taking responsibility of the overall content as guarantor. NSA: examined, analysed and interpreted investigative data. IAA: analysed and interpreted investigative data. $\mathrm{CM}$ : analysed and interpreted investigative data, reviewed the manuscript. VFK: designed the manuscript construct, critically reviewed the manuscript. All authors read and approved the final manuscript.

Funding The authors acknowledged the financial assistance for publication received from the Universiti Kebangsaan Malaysia University Research Grant KOMUNITI/2011/019.

Competing interests None declared.

Patient and public involvement Patients and/or the public were not involved in the design, or conduct, or reporting, or dissemination plans of this research.

Patient consent for publication Not applicable.

Ethics approval This study received approval from University Kebangsaan Malaysia Research Ethics Committee UKM 1.5.3.5/244/SPP2/NN/187/2010.

Provenance and peer review Not commissioned; externally peer reviewed.

Data availability statement All data relevant to the study are included in the article.

Open access This is an open access article distributed in accordance with the Creative Commons Attribution Non Commercial (CC BY-NC 4.0) license, which permits others to distribute, remix, adapt, build upon this work non-commercially, and license their derivative works on different terms, provided the original work is properly cited, appropriate credit is given, any changes made indicated, and the use is non-commercial. See: http://creativecommons.org/licenses/by-nc/4.0/.

ORCID iD

Rokiah Omar http://orcid.org/0000-0001-9485-1620

\section{REFERENCES}

1 Thylefors B. Epidemiological patterns of eye injury. Australian New Zealand J Ophthalmol 1992;20:95-8.

2 National center for health statistics' health interview survey, 1977. Available: www.useironline.org/Prevention.htm

3 Kuhn F, Mester V, Witherspoon CD, et al. Epidemiology and socioeconomic impact of eye injury. vitreoretinal surgery of injured eye. Philadelphia: Lippincott-Raven, 1999: 17-24.

4 National Society to Prevent Blindness. Vision problems in the U.S.: data analysis. New York: NSPB, 1980: 25-6.

5 Thevi T, Basri M, Reddy S. Prevalence of eye diseases and visual impairment among the rural population - a case study of temerloh hospital. Malays Fam Physician 2012;7:7-6.

6 Movahedinejad T, Adib-Hajbaghery M, Zahedi MR. A study on hospital admissions for eye injury in Kashan, Iran. Injury 2016;21.

7 Milanez M, Saraiva PGC, Barcellos NN, et al. Epidemiological and occupational profile of eye trauma at a referral center in Espírito Santo, Brazil. Rev Bras Oftalmol 2017;76:7-10.

8 Thevi T, Reddy SC. Review of eye injuries in Malaysia. Malaysian J Public Health Med 2017;17:69-77.

9 Voon LW, See J, Wong TY. The epidemiology of ocular trauma in Singapore: perspective from the emergency service of a large tertiary hospital. Eye 2001;15:75-81.

10 Soong TK-W, Koh A, Subrayan V, et al. Ocular trauma injuries: a 1-year surveillance study in the University of Malaya medical centre, Malaysia. 2008. Graefes Arch Clin Exp Ophthalmol 2011;249:1755-60. 
11 Madhusudhan ALP, Evelyn-Tai LM, Zamri N, et al. Open globe injury in Hospital Universiti Sains Malaysia - A 10-year review. Int J Ophthalmol 2014;7:486-90.

12 Mallika P, Tan A, Asok T. Pattern of eye injury in Kuching, Sarawak, Malaysia. Malaysian Fam Phys 2008;3:140-5.

13 Omar R, Knight VF, Aziz Mohammed MA. Low vision rehabilitation and ocular problems among industrial workers in a developing country. Malays Fam Physician 2014;9:27.

14 Kuhn F, Morris R, Witherspoon CD, et al. The Birmingham eye trauma terminology system (BETT). Journal Français d'Ophtalmologie 2004;27:206-10.

15 Fricke TR, Tahhan N, Resnikoff S, et al. Global prevalence of presbyopia and vision impairment from uncorrected presbyopia: systematic review, meta-analysis, and modelling. Ophthalmology 2018;125:1492-9.

16 Lai YK, Moussa M. Perforating eye injuries due to intraeye foreign bodies. Med J Malaysia 1992;47:212-9.

17 Zainal M, Goh PP. A study of perforating eye injuries at the ophthalmology department, National University of Malaysia. Med $J$ Malaysia 1997;52:12-16
18 Hooi SH, Hooi ST. Open-globe injuries: the experience at hospital Sultanah Aminah, Johor Bahru. Med J Malaysia 2003;58:405-12.

19 Reddy SC, Tahunisah I. Chemical injuries of eye. A review of 75 cases from West Malaysia. Int J Ophthalmol 2007;7:327.

20 Adlina A-R, Chong Y-J, Shatriah I. Clinical profile and visual outcome of traumatic paediatric cataract in suburban Malaysia: a ten-year experience. Singapore Med J 2014;55:253-6.

21 Rashid RA, Heidary F, Hussein A, et al. Ocular burns and related injuries due to fireworks during the Aidil Fitri celebration on the East coast of the Peninsular Malaysia. Burns 2011;37:170-3.

22 Ngo CS, Leo SW. Industrial accident-related ocular emergencies in a tertiary hospital in Singapore. Singapore Med J 2008;49:280-5.

23 Ho C-K, Yen Y-L, Chang C-H, et al. Epidemiologic study on workrelated eye injuries in Kaohsiung, Taiwan. Kaohsiung J Med Sci 2007;23:463-9.

24 Kaufman A. The compliance resource center a safer worker, 2009.

25 Prevent Blindness America. Workplace eye safety programs, 2011. Available: http://preventblindness.org 